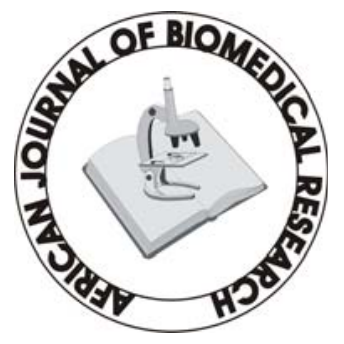

Full-text available at http://www.ajbrui.com http://www.bioline.br/md http://www.ajol.com

Received:

February 2006

Accepted (Revised): August 2006

Published

September 2006
Full Length Research Article

\section{In-vitro Anti-Microbial and Brine-Shrimp Lethality Potential of the Leaves and Stem of Calotropis procera (Ait).}

\author{
${ }^{* 1}$ Oladimeji, H.O, ${ }^{2}$ Nia, R and ${ }^{1}$ Essien, E. E.
}

1 Department of Pharmaceutical and Medicinal Chemistry, Faculty of Pharmacy, University of Uyo, Uyo

2 Department of Pharmacognosy and Traditional Medicine, Faculty of Pharmacy,

University of Uyo, Uyo

\section{ABSTRACT}

Calotropis procera (Family, Asclepiadeae) is implicated in a variety of ethno-medicinal therapies ranging form oral, skin, gastro-intestinal to respiratory problems. The effects of this plant on the sensitivity of microorganisms need verification and its potential for cytotoxicity needs to be investigated. Thus, the anti-microbial and brine-shrimp lethality studies on the leaves and stem were carried out. The crude ethanolic extract of the stem and its ethylacetate fraction elicited good antibacterial activity against clinical strains of Bacillus subtilis, Staphylococcus aureus but gave minimal activity against Escherichia coli, Klebsiella pneumoniae and Salmonella typhi but none against the fungal isolate; Candida albicans. The brine-shrimp lethality assay analyzed using the Finney probit method showed that the crude ethanolic extracts of the leaves and stem displayed $L D_{50}$ values at 192 ppm and 182 ppm respectively. These findings indicate the potential of the plant as panacea for infectious diseases and also reveal a novel potential in the fight against tumors in man. (Afr. J. Biomed. Res. 9: 205 - 211)

Keywords: Anti-microbial, extracts, fractions, brine-shrimp lethality, Calotropis procera

*Address for Correspondence (e-mail): (08023348195, wale430@yahoo.co.uk).

Abstracted by:

African Index Medicus (WHO), CAB Abstracts, Index Copernicus, Global Health Abstracts, Asian Science Index, Index Veterinarius, Bioline International , African Journals online 


\section{INTRODUCTION}

The genus, Calotropis belongs to the Family, Asclepiadeae. The species found in this genus include C.busseana,C.inflexa,C.syrica and C.procera.Calotropis procera(Ait) is a droughtresistant, salt-tolerant weed found along degraded roadsides, lagoon edges and in overgrazed pastures. It is native to Nigeria and many other countries in tropical Africa, Asia and Latin America where the plant is of high socio-economic value (F.A.O.1986; Abbas et al,1992).

The bark is used traditionally in the treatment of coughs, dermatitis, dysentery, elephantiasis, jaundice, leprosy, sore-gums swellings and ulcers(von Maydell,1986). It is also used in dehairing hides, tanning, brewing, curdling milk and as an arrow and spear poison (Leeuwenberg,1987).

The latex is used on conjunctiva, epiphora, in local anesthesia, to treat ringworm and other skin diseases. It also serves as a source of renewable energy, hydrocarbons (Arora,1982), green manure, sulphur dioxide emission and an indication of exhaust soil (Leeuwenberg,1987).

The flower is used as a digestive, tonic for asthma and catarrh while the sap serves as a rubefacient and purgative. The floss of the seeds is used as substitute cotton wool in surgical operations (von Maydell, 1986).

The leaves are eaten by goats, occasionally sheep in times of need but rarely by cattle and other livestock because they are slightly toxic. The stem is used in native roofing of huts and also as source of charcoal (Taylor,2004). Compounds such as asclepsin and mudarin reportedly isolated from this plant have been found to posses emeto-cathartic, digitalic, bactericidal and vermicidal properties while calotropin is cardio-toxic (Taylor,2004).

Consequently, this study was embarked upon to confirm or otherwise, the sensitivity of microbes to extracts of the plant and also to investigate its potential for cytotoxic activity

\section{MATERIALS AND METHODS \\ Plant collection, identification and authentication.}

The fresh leaves and stem of Calotropis procera (Ait) were collected throughout the month of
November, 2004 at a location inside the University of Uyo (Main campus) Uyo, Akwa Ibom State. These plant parts were identified and authenticated by the taxonomist of Faculty of Pharmacy where voucher specimens (NoH43) and (NoH44) were deposited.

Chemicals, media, micro-organisms and other materials.

Chemical reagents: The reagents used in this study were, Butanol, Chloroform, Ethanol and Methanol; all of AnalaR grade(East Anglia Chemicals Limited, England), Silica gel (254GF), Streptomycin sulphate and Nystatin(Unique Pharmaceuticals, Lagos, Nigeria).

Culture media: The media used were Mueller Hinton II Agar (Biotec Oxiod Limited, England, No13904) and Sabouraud Dextrose Agar (International Diagnostic Group, England, No049041).

Micro-organisms:_The micro-organisms(Bacillus subtilis, Staphylococcus aureus, Escherichia coli, Klebsiella pneumoniae, Salmonella typhi and Candida albicans) clinically isolated from human specimens; urine, faeces, wounds and vaginal swabs originally obtained from the University of Uyo Teaching Hospital, Uyo were collected in sterile bottles and refrigerated at $0-5^{0} \mathrm{C}$. They were then subjected to laid down convectional biochemical methods (Gibson and Khoury,1986; Murray et $a l, 1985)$ for identification and preservation.

\section{Other materials:}

Sea water was collected from Kuramo Beach, Lagos, brine- shrimp eggs; Artemia salina (Leach) (San Francisco Bay Brand Inc. Newark, CA 94560, U.S.A.) and plastic soap case.

\section{Extraction and processing}

The plant parts i.e. the leaves and stem of $C$. procera were air -dried and powdered respectively on an electric mill. The resultant ground powders were then extracted with $50 \%$ aqueous ethanol at room temperature $\left(25^{0} \mathrm{C}\right)$ for $72 \mathrm{~h}$. The filtrates were 
evaporated to dryness using a rotary evaporator (Buchi CH-9230, Laboratorium-Technic,Flawk/SG, Switzerland). The dried crude ethanolic extracts were then investigated for plant metabolites (alkaloids, saponins, tannins, cardiac glycosides, terpenes, anthraquinones, phlobotannins

and flavonoids) as described in phytochemical methods (Stahl et al,1965;Brain and Turner,1975;Harbone,1984; Akerele,1984;Trease and Evans,1989).

The dried crude ethanolic extracts were dissolved in water and then chromatographed respectively on silica gel (254GF) column with chloroform: ethylacetate: butanol(1:1:1) mixture in a gradient elution. Eluates showing similar (T.L.C) profiles were pooled and bulked separately resulting in chloroform, ethylacetate and butanol fractions which were evaporated to dryness and then subjected to anti-microbial screening.

\section{Anti-microbial sensitivity test:}

The media (Mueller Hinton II Agar and Sabouraud Dextrose Agar) were prepared according to Manufacturers' instructions, poured into large sterile petri-dishes (diameter, $13.5 \mathrm{~cm}$ ) and allowed to set. The Agar-cup diffusion method was employed for the anti-microbial susceptibility testing. $20 \mathrm{ml}$ of the media agar seeded with $0.1 \mathrm{ml}$ of $10^{-2}$ dilution of the organisms were introduced into the petri-dishes. After solidification, uniform and equidistant wells of $6 \mathrm{~mm}$ diameter were cut in the agar by using a sterile cork- borer(Washington,1995).

Concentrations of $20 \mathrm{mg} / \mathrm{ml}$ and $40 \mathrm{mg} / \mathrm{ml}$ of the dried crude ethanolic extracts and the fractions at $5 \mathrm{mg} / \mathrm{ml}$ dissolved in de-ionized water were separately introduced into wells. Also, concentrations of $1 \mathrm{mg} / \mathrm{ml}$ of Streptomycin sulphate, $1 \mathrm{mg} / \mathrm{ml}$ of Nystatin and de-ionized water were introduced into separate wells as positive and negative controls respectively. The experiments were carried out in triplicates. The plates were left at room temperature $\left(25-30^{\circ} \mathrm{C}\right)$ for $2 \mathrm{~h}$ to allow for diffusion and then incubated at $37^{\circ} \mathrm{C}$ for $24 \mathrm{~h}$.

Zones of growth inhibition were measured in millimeters (mm). Thereafter, the minimum inhibitory concentration (M.I.C.); the lowest concentration of a sample that inhibits the growth of a micro-organism was determined by the standard serial dilution technique (Hugo and Russel, 1994; Washington,1995) using the Mueller Hinton II Agar and Sabouraud Dextrose Agar as media for the bacteria and fungus respectively.

\section{Brine-shrimp lethality assay Hatching of shrimp eggs}

Some sea water was placed in a small plastic with perforated dividing dam which was fabricated from a plastic soap case. Some shrimp eggs were added to one side of the divided dam tank. This side was darkened by covering it with a plastic lid while the other compartment was exposed. The set- up was left for $48 \mathrm{~h}$ for the shrimp eggs to hatch and mature as nauplii. Mature nauplii usually swim to the exposed compartment.

\section{Preparation of vials for testing}

A stock solution of sample was prepared by dissolving 20mg of the sample in $2 \mathrm{ml}$ methanol/deionized water $(1: 1 \mathrm{v} / \mathrm{v})$. To obtain the desired final concentrations such as $1000 \mu \mathrm{g} / \mathrm{ml}, 100 \mu \mathrm{g} / \mathrm{ml}$ and $10 \mu \mathrm{g} / \mathrm{ml} ; 0.5 \mathrm{ml}, 0.05 \mathrm{ml}$ and $0.005 \mathrm{ml}$ of the stock were transferred into the three vials respectively.

The solvent was then evaporated by leaving the vials in a vacuum desiccator for $24 \mathrm{~h}$. Ten shrimp nauplii were counted into each vial(i.e.30 nauplii per dilution). The total volume of solution in each vial was adjusted to $5 \mathrm{ml}$ by adding the sea water (5ml/vial). The control (methanol/de-ionized water $(1: 1 \mathrm{v} / \mathrm{v})$ was prepared in the same way except that the sample was omitted. The vials were maintained in the laboratory with normal fluorescent illumination and the set-up left for 24h.The number of survivors usually swimming was counted with the aid of a magnifying lens for each of the vials at the end of 24h.Thus, the number of the dead was computed; hence the $\mathrm{LD}_{50}$ in p.p.m. (parts per million) was determined using the Finney probit analysis software (McLauglin,1988; McLauglin et al,1991).

\section{RESULTS AND DISCUSSION}

The phytochemical screening of the crude ethanolic extracts of leaves and stem of Calotropis procera showed that they both contain alkaloids, 
saponins, tannins, cardiac glycosides, terpenes, flavonoids and phlobotannins (Table 1).This confirms previous studies as reported in Taylor (2004). However, anthraquinones were absent in both extracts.

From the anti-microbial results presented on Table 2, it could be inferred that the extracts elicited concentration-dependent activities. The crude ethanolic extract of the stem gave higher antibacterial activity against B.subtilis and S.aureus than the extract of the leaves. However, the activity given by both extracts against E.coli, K.pneumoniae and S.typhi were comparably less.(Table 2).This is not surprising because both extracts tested positive for tannins which had been implicated in previous studies to be anti-microbial (Adesina, et al, 2000;Burapadaja and Bunchoo,1995).It is very probable that these bioactive compounds might have played a significantly similar role in the observed activity. Furthermore, these results have partly justified some of the uses of the plant in ethnomedicine (von Maydell,1986).

The activity recorded by these extracts then necessitated their purification by chromatography into fractions.
Table 1.

The phytochemical screening of the crude ethanolic extracts of leaves and stem of Calotropis procera(Ait).

$$
\text { Test }
$$

A $\quad$ B

1. Alkaloids:

(a) Dragendoff's

(b) Meyer's

2.Saponins:

(a) Frothing

(b) Emulsion

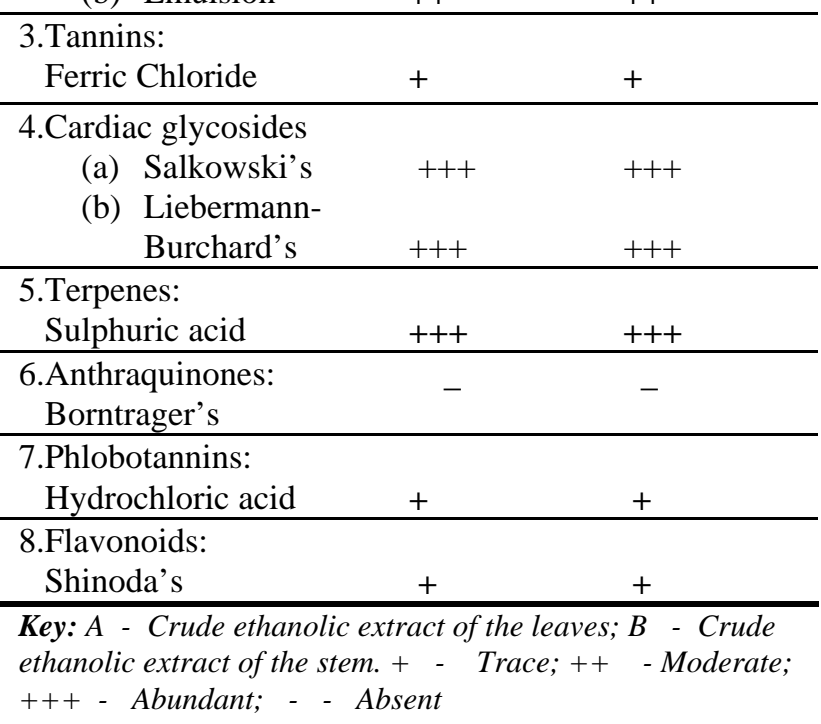

Table 2.

The antimicrobial sensitivity of the crude ethanolic extracts and fractions of leaves and stem of Calotropis procera in de-ionized water.

\begin{tabular}{|c|c|c|c|c|c|c|c|c|c|c|c|c|c|}
\hline \multirow[t]{3}{*}{ Test organism } & \multicolumn{13}{|c|}{ Diameter of zone of inhibition in millimeters $(\mathrm{mm}) \_0.5 \mathrm{~mm}$} \\
\hline & \multicolumn{2}{|c|}{$\mathrm{A} / \mathrm{mg} / \mathrm{ml}$} & \multirow{2}{*}{\multicolumn{3}{|c|}{$\begin{array}{ll}A_{1} \quad A_{2} \quad A_{3} \\
\\
\end{array}$}} & \multicolumn{2}{|c|}{$\mathrm{B} / \mathrm{mg} / \mathrm{ml}$} & \multirow{2}{*}{\multicolumn{3}{|c|}{$\begin{array}{cc}\mathrm{B}_{1} & \mathrm{~B}_{2} \quad \mathrm{~B}_{3} \\
& \\
& 5 \mathrm{mg} / \mathrm{ml}\end{array}$}} & \multirow{3}{*}{$\begin{array}{c}\text { STP } \\
1 \mathrm{mg} / \mathrm{ml} \\
10\end{array}$} & \multirow{3}{*}{$\begin{array}{c}\text { NYS } \\
1 \mathrm{mg} / \mathrm{ml} \\
12\end{array}$} & \multirow{3}{*}{$\begin{array}{c}\text { CN } \\
\\
\\
6\end{array}$} \\
\hline & 20 & 40 & & & & \multirow{2}{*}{$\begin{array}{l}\mathbf{2 0} \\
13\end{array}$} & \multirow{2}{*}{$\begin{array}{l}\mathbf{4 0} \\
14\end{array}$} & & & & & & \\
\hline B. subtilis & 10 & 12 & 14 & 15 & 14 & & & 14 & 18 & 15 & & & \\
\hline S.aureus & 11 & 13 & 13 & 16 & 14 & 14 & 15 & 14 & 18 & 16 & 19 & 11 & 6 \\
\hline E. coli & 9 & 11 & 10 & 12 & 11 & 10 & 12 & 10 & 14 & 12 & 15 & 12 & 6 \\
\hline K.pneumoniae & 9.5 & 11 & 11 & 13 & 12 & 11 & 12 & 11 & 14 & 13 & 15 & 10 & 6 \\
\hline S.typhi & 10 & 11 & 11 & 13 & 11.5 & 10 & 11 & 10 & 11 & 12.5 & 16 & 10 & 6 \\
\hline C.albicans & 7 & 7.5 & 7.5 & 7.5 & 7.5 & 7.5 & 8 & 8 & 8 & 8 & 10 & 20 & 6 \\
\hline
\end{tabular}

Key: *The diameter of zone of inhibition is zone of inhibition and cup-size (6mm)

A - Crude ethanolic extract of leaves; $A_{1}$ - Chloroform fraction of $A ; A_{2}$ - Ethylacetate fraction of $A$

$A_{3}$ - Butanol fraction of $A ; B$ - Crude ethanolic extract of stem; $B_{1}$ - Chloroform fraction of $B$; $B_{2}$ - Ethylacetate fraction of $B$;

$B_{3}$ - Butanol fraction of B; STP - Streptomycin sulphate; NYS Nystatin; CN Control (De-ionized water) 
Table 3.

The minimum inhibitory concentration (M.I.C.) of the crude ethanolic extracts and the ethylacetate fractions of leaves and stem of Calotropis procera on test microbes

\begin{tabular}{|c|c|c|c|c|c|c|}
\hline \multirow[t]{2}{*}{ Test microbe } & \multicolumn{6}{|c|}{ M.I.C. $(\mu \mathrm{g} / \mathrm{ml})^{\mathbf{a}}$} \\
\hline & A & B & $\mathrm{A}_{2}$ & $\mathrm{~B}_{2}$ & STP & NYS \\
\hline B. subtilis & 400 & 300 & 300 & 250 & 1.8 & ND \\
\hline S. aureus & 400 & 350 & 350 & 300 & 3.2 & ND \\
\hline E. coli & 400 & 400 & 300 & 300 & 8.3 & 9.2 \\
\hline K. pneumoniae & 400 & 400 & ND & 300 & 100 & ND \\
\hline S. typhi & 400 & 400 & ND & ND & ND & ND \\
\hline C. albicans & 500 & 500 & ND & ND & ND & 90 \\
\hline
\end{tabular}

ND-Not detected.

Table 4.

The brine-shrimp lethality assay of the crude ethanolic extracts of leaves and stem of Calotropis procera

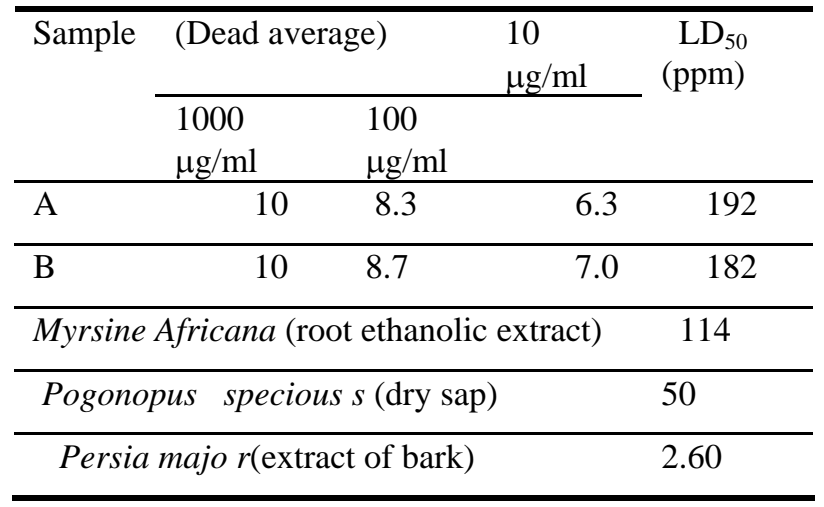

Expectedly, the fractions afforded greater antibacterial activity against the test organisms than the activity given by their respective mother extracts (Table 2).This could be attributed to level of purity inherent in the fractions.

It was observed that among the fractions, the ethylacetate fractions gave the highest antibacterial activity while the chloroform fractions recorded the least. This was so because the extracts were largely insoluble in chloroform, thereby affording insoluble fractions which gave comparably smaller antibacterial activity.(Table 2).

However, the crude ethanolic extracts and the fractions demonstrated poor anti-fungal activity against C.albicans. This could be due to the nature of the fungus; its structure differing from the cellwall of bacteria and resembling those of higher plants, hence limiting the permeation of substances into it.

The results of the M.I.C. determinations as presented on Table 3 generally show that higher concentrations of the extracts were required it inhibit the growth of the microbes than those required of the fractions. The same reason of level of purity applies.

The brine-shrimp assay determines the lethalities of materials toward brine-shrimp larvae (nauplii) and in doing so predicts the ability to kill cancer cells in cell-cultures, kill various pests and exert a wide range of pharmacologic effects. The shrimp nauplii have been used for a number of bioassay systems in which natural products extracts, fractions or pure isolates are tested at concentration of $1000 \mu \mathrm{g} / \mathrm{ml}, 100 \mu \mathrm{g} / \mathrm{ml}$ and $10 \mu \mathrm{g} / \mathrm{ml}$ in vials containing $5 \mathrm{ml}$ of brine and ten nauplii in each of the three replicates (Meyer et al,1982).The $\mathrm{LD}_{50}$

values in p.p.m. are estimated with 95\% confidence using the appropriate mathematical estimates; the Finney probit analysis program being the model routinely employed.

The $\mathrm{LD}_{50}$ values of the crude ethanolic extracts of leaves and stem of C.procera and other plants in literature (Kupahan et al, 1969; Ma et al 1989; Ma et al 1990; McLauglin et al,1991) are presented on Table 4.The results show that both extracts(leaves and stem) $C$. procera displayed $\mathrm{LD}_{50}$ values of $192 \mathrm{ppm}$ and 182ppm. These values compare favorably with those of Myrsine Africana (114ppm), Pogonopus speciosus (50ppm) and Persia major (2.6ppm) whose $\mathrm{LD}_{50}$ values below the 200ppm are generally considered as 'significant'((Kupahan et al,1969; Ma et al,1989; Ma et al,1990;McLauglin et al,1991; Oladimeji et al, 2005).This is to be expected because the crude ethanolic of the leaves 
and stem tested positive for saponins (Table 1).This class of metabolites had been implicated in previous studies to be cytotoxic (Kupahan et al,1969). These particular results obtained in this study have revealed a novel potential of the plant in the fight against tumors in man.

\section{REFERENCES}

Banerji S, Bhowmick S, Bera M, Pal M, Pal SP (1991): Antinociceptive action of GABA-mimetic agent-N-Phthaloyl GABA. Indian. J Exp Biol 6: 538-542.

Banierji S, Habibuddin M, Pal SP (1992): Antiulcer and gastric secretory activity of $\mathrm{N}$ Phthaloyl gamma-aminobutyric acid. Eur $J$ Pharmacol 25: 211-215.

Baran D, Panduraru I, Saramet A, Petrescu E, Haulica I (2000): Influence of light-dark cycle alteration on free radical in rat CNS. Rom J Physiol 37: 23-38.

Baydas G, Gursu MF, Yilmaz S, Cannoplat S, Yasar A, Cilkim G, Canatan H (2002): Daily rhythm of glutathione peroxidase activity, lipid peroxidation and glutathione levels in tissues of pinealoctomized rats. Neurosci Lett 323: 195-198.

Bhowmick S, Bose R, Pal M, Pal SP (1990): Antiulcer activity of N-Phthaloyl GABA-a new GABA mimetic agent. Ind J Exp Biol 28: 190-192.

Bhowmick S, Pal M, Pal SP (1989): Synthesis and anticonvulsant activity of N-Phthaloyl GABA-a new GABA derivative. Ind J Exp Biol 27: 805-808.

Decavel C, Van den pol AN (1990): GABA a dominant neurotransmitter in the hypothalamus. Journal of Comparative Neurology 302: 1019-1037. Ellman GL (1959): Tissue sulphydryl groups. Arch. Biochem. Biophys. 82:70-77,

Farooqui MY, Ahmed AE (1984): Circadian periodicity of tissue glutathione and its relationship with lipid peroxidation in rats. Life Sci 34: 24132418.

Habibuddin M, Pal M, Pal SP (1982): Neuropharmacology of amide derivatives of PGABA. Ind J Exp Biol 30: 578-582.

Hendrickson AE, Ogren MP, Vaughan JE, Barber RP, Wu JY (1983): Light and electron microscope immunocytochemical localization of glutamic acid decarboxylase in monkey geniculate complex: Evidence for GABAergic neurons and synapses. J Neurosci 3: 1245-1262.

Hodoglugil U, Ongun O, Guney Z, Altan N, Zengil $H$ (1995): Temporal variation in hepatic superoxide dismutase activity in mice. Chronobiol Int 12: 152-155.

Kakkar P, Dos B, Viswanathan PN (1984): A modified spectrophotometric assay of superoxide dismutase. Ind J Biochem Biophys 21: 130-132.

Kulkarni SK, Kunchandy J (1998): In brain and psychophysiology of stress, edited by K.N Sharma, W Selvamurthy and V Bhattacharya (Indian Council of Medical Research, New Delhi) 191.

Lowe IP, Robins E, Eyerman GS (1958): Determination of brain GABA level by spectrofluorimetry. J Neurochem 3: 8.

Manivasagam T, Subramanian $P$ (2004): Influence of monosodium glutamate on circadian rhythms of lipid peroxidation products and antioxidants in rats. The Italian J Pharmacol 53: 7276.

Mirunalani S, Subrmanian P (2004): Temporal oscillations of thyroid hormones in long term melatonin treated rats. Pharmazie 60: 52-56

Moore RY, Speh JC (1993): GABA is principal neurotransmitters of the circadian system. Neurosci Lett 150: 112-116.

Myers RD (1975): Blood brain barrier technique for the intracerebral administration of drugs. In: Iversen, L.L; Iversen, S.D; Sryder, S.H., eds. Handbook of psychopharmacology, Vol.2. New York: Plenum Press; 1-28.

Nichans WG, Samuelson B (1986): Formation of malondialdehyde from phospholipid arachidonate during microsomal lipid peroxidation. Eur $J$ Biochem 6: 126-130.

Rajakrishanan V, Subramanian S, Viswanathan P, Menon VP (1999): Effects of chronic ethanol ingestion on Biochemical circadian rhythms in Wistar rats. Alcohol 18: 147-152.

Ralph MR, Menaker M (1989): GABA regulation of circadian responses to light. Involvement of GABA-benzodiazepine and GABAB receptors. $J$ Neurosci 9: 2858-2865.

Reppert SM, Weaver DR (2001): Molecular analysis of mammalian circadian rhythms. Annu Rev Physiol 63: 647-678. 
Schibler U, Ripperger J, Brown SA (2003): Peripheral circadian oscillations in mammals: time and food. J Biol Rhythms 18: 250-260.

Sen S, Habibuddin M, Pal SP (1994): Antinociaptive action and N-Octanoyl GABA-a new GABA mimetic agent. Ind J Exp Biol 32: 718-723.

Singh JPV, Selvendiran K, Mumtaz Bansu S (2004): Protective role Apigenin on the status of lipid peroxidation and antioxidant defense against hepatocarcinogenesis in Wistar albino rats. Phytomedicine 11: 309-393.

Sinha AK (1972): Colorimetric assay of catalase. Anal Biochem 47: 389-384.

Solar P, Ahlers I (1997): Circadian oscillations of lipid peroxidation in the rat pineal gland. Physiol Res 46: 323-325.

Subramanian P, Menon VP, Arockiam, FV, Rajakrishnan V, Balamurugan E (1998): Lithium modulates biochemical circadian rhythms in Wistar rats. Choronobiol Int 15: 29-38.

Subramanian P, Subbaraj R (1993): Diazepam phase shifts the circadian clock of the field mouse Musbooduga. J Biosci 18: 103-110.

Subramanian P, Sundaresan S, Balamurugan E
(1998): Temporal oscillations of phosphatases in $\mathrm{N}$ Phthaloyl gamma-aminobutyric acid treated rats. Ind J Exp Biol 36: 1141-1143.

Subrmanian P, Subbaraj R (1996): Diazepam modulates the period of locomotor rhythm in mice (musbooduga) and attenuates light-induced phase advances. Pharmacol Biochem Behav 54: 393-398. Turek FW, Losee-Olson SH (1987): Dose response curve for the phase shifting effect of triazolam on the mammalian circadian clock. Life Sci 40: 10331038.

Wagner S, Castel M, Gainer H, Yarom Y (1997): GABA in the mammalian suprachiasmatic nucleus and its role in diurnal rhythmicity. Nature 387: 598603.

Wu JY, Brandon C, Su YYT, Lam DMK (1981): Immunocytochemical and autoradiographic localization on GABA system in the vertebrate retina. Mol Cell Biochem 39: 229-238. 